\title{
Do people adjust career choices according to socioeconomic conditions? An evolutionary analysis of future discounting
}

\author{
Monique Leitão ${ }^{1,2}$, Álvaro Guedes ${ }^{3}$, Maria EmíliaYamamotoํ, and Fívia de Araújo Lopes ${ }^{1}$ \\ 1. Universidade Federal do Rio Grande do Norte, Natal, RN, Brazil \\ 2. Instituto Federal de Educação, Ciência e Tecnologia do Rio Grande do Norte, Natal, RN, Brazil \\ 3. Universidade Federal de Ciências da Saúde de Porto Alegre, Porto Alegre, RS, Brazil
}

\begin{abstract}
The ability to process environmental cues and make advantageous choices has been fundamental during human evolution. Discounting future rewards is a capacity of our evolved mind and could be useful for understanding career decisions. This paper investigated the relationship between real-life plans, career choices, and income indicators based on an evolutionary approach of future discounting. Study 1 analyzed the plans of 200 senior high school students, and Study 2 analyzed a database of 46,649 applicants to a Brazilian public university. The results demonstrated that lower income subjects made career decisions with quicker returns and smaller investments. They included a job in immediate plans more frequently than higher income students who planned to go to a university. Analyzing the applicants' choices, higher income subjects sought courses with greater entrance difficulty. We suggest that individuals adjust career plans and choices according to their socioeconomic conditions and assume different discounting rates by considering risks of failure and future gains. Keywords: future discounting, career choice, evolutionary psychology, income, adolescent.
\end{abstract}

Received 17 May 2013; received in revised form 15 October 2013; accepted 16 October 2013. Available online 23 December 2013.

\section{Introduction}

From an evolutionary perspective, human psychological mechanisms are a result of selective pressures that operated on our ancestors over the course of the evolutionary process (Tooby, \& Cosmides, 1992). The ability to process environmental cues and make more advantageous choices was fundamental during the evolutionary history of our species. Analyzing the circumstances and deciding to invest in lower shortterm gains or risk higher long-term gains is one of the capacities of our evolved mind.

Monique Leitão, Laboratório de Evolução do Comportamento Humano, Departamento de Fisiologia, Programa de Pós Graduação em Psicobiologia, Universidade Federal do Rio Grande do Norte, and Instituto Federal de Educação, Ciência e Tecnologia do Rio Grande do Norte Natal, RN, Brazil. Maria Emília Yamamoto and Fívia de Araújo Lopes, Laboratório de Evolução do Comportamento Humano, Departamento de Fisiologia, Programa de Pós Graduação em Psicobiologia, Universidade Federal do Rio Grande do Norte, Natal, RN, Brazil. Álvaro Guedes, Universidade Federal de Ciências da Saúde de Porto Alegre, Porto Alegre, RS, Brazil. Correspondence regarding this article should be directed to: Monique Leitão, Universidade Federal do Rio Grande do Norte, Campus Universitário, Caixa Postal 1511, Lagoa Nova, Natal, RN, CEP 59078-970, Brazil. Phone: +55 (84) 32153409. Fax: +55 (84) 32119206. E-mail: moniqueleitao@ yahoo.com.br
The extent to which we opt for immediate gains over future rewards is known as future discounting (Wilson, \& Daly, 2004). This phenomenon has been studied by different fields, such as psychology, economics, biology, and criminology, among others, using various methods (Hardisty, \& Weber, 2009; Matta, Gonçalves, \& Bizarro, 2012; Muramatsu, \& Fonseca, 2008). However, psychology has traditionally described these behaviors with terms such as impulsivity, myopia, or lack of self-control, assuming that discounting behaviors are dysfunctional, regardless of the situation, socioeconomic factors, and the age of the subject (Daly, \& Wilson, 2005).

The evolutionary perspective is innovative by raising the notion that future discounting may be a functional and adaptive response to specific situations, particularly uncertainty or the low probability of reaping delayed benefits (Charlton, 1996; Rogers, 1994; Wilson, \& Daly, 1997). Thus, discount rates understandably vary adaptively according to various factors, such as sex, life span, social circumstances, and environmental situations.

Studies with animals, such as wasps, honey bees, and scorpionflies, have shown that organisms tend to discount the future under certain situations (i.e., they bet on risky behaviors and present gains based on environmental cues that indicate low life expectancy or narrow future options; Engqvist, \& Sauer, 2002; 
Roitberg, Mangel, Lalonde, Roitberg, van Alphen, \& Vet, 1992; Roitberg, Sircom, Roitberg, van Alphen, \& Mangel, 1993; Woyciechowski, \& Kozlowski, 1998). Among nonhuman primates, investigations demonstrated that feeding ecology could explain some differences between species with regard to the capacity to wait for rewards (Stevens, Hallinan, \& Hauser, 2005). Other studies verified that monkeys avoid risky options with increasing delay (Hayden, \& Platt, 2007), and they tend to choose a small reward when the large one is delayed (Hwang, Kim, \& Lee, 2009). Apes show a higher ability for future-oriented decisions than other animals, presenting temporal discounting preferences that are similar to humans under comparable conditions (Rosati, Stevens, Hare, \& Hauser, 2007).

Human studies generally involve experiments in which different monetary sums are offered after different time intervals (Frederick, Loewenstein, \& O'Donoghue, 2002). These studies, for example, have investigated discount rates between men and women (Kirby, \& Marakovic, 1996), between age groups (Green, Fry, \& Myerson, 1994; Green, Myerson, \& Ostaszewski, 1999; Mischel, Shoda, \& Rodriguez, 1989; Steinberg, Graham, O'Brien, Woolard, Cauffman, \& Banich, 2009; Whelan, $\&$ McHugh, 2009), and between specific groups, as in the case of young offenders (Wilson, \& Daly, 2006), drug addicts, and smokers (Kirby, Petry, \& Bickel, 1999; Kollins, 2003; Reynolds, Patak, \& Shroff, 2007). Future discounting has also been investigated using other methods, including experimental manipulations (Wilson, \& Daly, 2004) and demographic database analysis (Wilson, \& Daly, 1997).

Among demographic investigations, various studies have examined the relationship between income indicators (e.g., mean income or income inequality) and variables such as life expectancy, criminality, and homicide rate (Kaplan, Kamuk, Lynch, Cohen, \& Balfour, 1996; Wilkinson, 1992). Other studies demonstrated an association between socioeconomic deprivation and faster life-history strategies involved in reproductive decisions (Ellis, Figueredo, Brumbach, \& Schlomer, 2009; Nettle, 2010), environmental unpredictability, and risk taking (Hill, Jenkins, \& Farmer, 2008) and between low income and choices for smaller-sooner amounts of money (Green, Myerson, Lichtman, Rosen, \& Fry, 1996; Harrison, Lau, \& Williams, 2002; Reimers, Maylor, Stewart, \& Chater, 2009). A recent study with a Brazilian sample showed that slum-dwelling young people discounted the future more than university students from middle-class neighborhoods in Rio de Janeiro, indicating that the young adapted their psychology and behavior to their living conditions (Ramos, Victor, Seidl-de-Moura, $\&$ Daly, 2013). These findings allow us to understand the influence of socioeconomic factors on the occurrence of future discounting.

Generally speaking, future discounting has been used to understand human decisions made under the influence of different variables and situations. We suggest that this perspective may be a useful tool for understanding a specific kind of choice, indeed an important choice that all of us have to make in our lives: the career choice.

Some studies demonstrated that individuals discount future outcomes in relation to career decisions similarly to other choice contexts. University students tended to prefer an immediate and less enjoyable job when the more enjoyable option was available after long delays (Hesketh, Watson-Brown, \& Whiteley, 1998). Graduating senior students tended to choose a job with delayed outcomes only if the reward was sufficiently high to offset the delay (Schoenfelder, \& Hantula, 2003). Among employees, the attractiveness of earlier promotion increased with the passage of time compared with long-term senior executive positions (Saunders, \& Fogarty, 2001). Theoretically, employees are more willing to tolerate non-stimulating jobs if they expect to advance in the near future (Fried, Grant, Levi, Hadani, \& Slowik, 2007).

However, the majority of the studies investigated hypothetical job decisions among university students or employees (i.e., subjects who already decided on a specified profession). Hirschi, \& Vondracek (2009) demonstrated that even before choosing a specific profession, adolescents expressed conflict in aligning their career aspirations to their environment and interests. They verified that Swiss students on basic school tracks who had more restricted opportunities for further education (e.g., post-secondary education) than students from advanced tracks tended to adapt their career goals to the opportunity structure of the environment (e.g., the availability of advanced schools and apprenticeships in their chosen occupation). In this sense, we suggest that earlier career-related decisions are also influenced by temporal aspects.

After finishing high school, individuals must decide what to do next: continue their academic studies or look for a job. These two main options lead to very different outcomes, temporally speaking. The first requires investing a number of years in the pursuit of a university degree, thereby postponing the immediate gains achieved by a job and income. The latter provides immediate rewards, although they tend to be less substantial in the long term than those accrued for professionals with a higher education. Therefore, the decision to pursue a university education has profound implications for both the future economic perspectives of the individual and the immediate gains from a paying job.

The present study was conducted in Brazil, and clarifying a number of peculiarities about university entry requirements is important. In our country, entrance to public universities is based almost exclusively on the results of multiple-choice and essay examinations, called vestibular, ${ }^{1}$ administered usually once per year. The number of vacancies offered by public universities-

1. This is true for 2006 and 2007, the years to which our data refer. The entry requirement system of Brazilian public universities is changing, and there are currently other ways to be admitted, in addition to vestibular. 
considered the best in the country - is very limited. In Natal, the capital of the state of Rio Grande do Norte, for example, in 2007, 22,249 applicants competed for the 3,506 vacancies offered by the Federal University of Rio Grande do Norte (Comperve - Comissão Permanente de Vestibular, 2007). These figures show the intense competition for admittance to Brazilian public universities. Accordingly, students consider the public university entrance examinations to be very important. The tests, which take place over a 3 or 4-day period at the end of the year, cover all of the subjects studied in high school. Applicants usually compete for entry into a single course. If they fail, then they must invest an entire year in preparation for the next vestibular.

Interestingly, the career choice is generally conceived as the result of factors related to the interests and aptitude of the individuals. Family influences, such as desires and expectations, are also considered in this process, but the influence of socioeconomic factors on this selection is not always given the proper attention. Although some authors consider socioeconomic factors to be important (Hall, \& Chandler, 2005), experimental studies do not emphasize the impact of these variables on the occupational choices of individuals. Additionally, research that has taken into account temporal influences in career choices generally included a small sample of university students or employees in relation to hypothetical career decisions instead of real-life career decisions.

The aim of the present study was to investigate the relationship between future plans, career choices, and income indicators based on an evolutionary analysis of future discounting. Our hypothesis was that individuals from families with different monthly incomes would plan their futures differently and seek undergraduate courses with different levels of entrance difficulty, owing to their distinct conditions for assuming the costs of failure and delaying future gains, thereby adopting career choices with different discount rates. Alternative explanations could also be offered for these options, especially with regard to the very low proportion of low-income individuals who seek university studies. However, we intend to show that these students exhibit future discounting compared with high-income individuals, although they invest more in their future than their low-income peers.

\section{Methods}

This paper presents the results of two different studies that considered real-life career plans and reallife career choices of the subjects. The data collection in Study 1 was part of a larger research project that was approved by the Ethical Committee of Federal University of Rio Grande do Norte (no. 137/05). In Study 2, we obtained permission from Federal University of Rio Grande do Norte's Comperve (Permanent Commission for Vestibular) for use of the applicants' database.

\section{Study 1: Future plans and income indicators}

To examine the relationship between income indicators and future plans, we used a sample of 200 senior high school students (133 girls and 67 boys). We chose these subjects because at the end of high school they must decide on their future, be it entry into the work force or further studies. The sample was composed of individuals aged between 15 and 19 years (mean age, $17.0 \pm .7$ years), around half of whom were enrolled in a public school (105 subjects), and the other half were enrolled in three private schools (95 subjects) in the city of Natal, Northeast Brazil.

Data were collected at the end of the school year using a questionnaire that investigated the students' plans for the following year (i.e., what they intended to do after graduating from high school).

Notably, Brazil has a clear socioeconomic distinction between students from public and private schools, with the former belonging to families with lower incomes than the latter. Official data from national research of households in 2006 (Instituto Brasileiro de Geografia e Estatística, 2007) classified the monthly family income per capita in quintiles (percentage of income for each fifth [20\%] of the population), ranging from the poorest $20 \%$ (first quintile) to the richest $20 \%$ (fifth quintile). According to this categorization, the majority of high school students enrolled in public schools $(51.3 \%)$ were between the second and third quintiles, whereas most of the students from private schools $(60.2 \%)$ were in the fifth quintile, namely the higher monthly family income per capita. The three private schools surveyed in this study were consulted about their scholarship availability, and the institutions informed that a very limited number of scholarships was offered; thus, this question does not significantly alter the average income of their students (personal communications, ${ }^{2}$ August 30, 2013). Therefore, the type of school in which the subject studies can be considered a good income indicator.

\section{Study 2: Career choice and income indicators}

In this study, we investigated career choices using the choice of the undergraduate course as a reference. We analyzed the official entrance examination data for 2006 and 2007 for Federal University of Rio Grande do Norte, Brazil, the largest and most respected university in our state. These data correspond to the 24,400 applicants in 2006 and 22,249 applicants in 2007 , for a total of 46,649 subjects. We analyzed the data for all 72 courses offered at the central campus in Natal.

The relationship between income and career choice was determined by comparing the family income of the subjects and entrance difficulty indicators of the various courses.

2. We omitted the names of the school principals who reported this information to maintain the confidentiality of the participating schools. 
Entrance difficulty indicators. The level of entrance difficulty for each course was measured using the mean number of correct answers obtained on the multiplechoice examinations by successful applicants on the previous year's examination. Thus, a higher percentage of correct answers obtained by the successful applicants was associated with more difficulty entering a particular course. We chose to analyze the results of the multiplechoice questions because they are identical for all of the applicants in all of the courses, thus allowing us to compare a homogeneous measure.

Another indicator of difficulty that we used was competition for a vacancy in a specific course, assessed by the applicant/vacancy ratio for each course. Thus, higher competition was associated with more difficulty securing a vacancy in the course.

Notably, every year Federal University of Rio Grande do Norte releases information on competition and minimum score (multiple-choice and essay examinations) attained by successful applicants in each of the courses offered the previous year. This information allows the applicants to analyze the difficulty level of the courses based on the previous year to help them choose the course to apply to.

Family income. As an indicator of income, we used the declared family income, measured in minimum monthly wages $(1$ minimum wage $[\mathrm{m} . \mathrm{w}]=.\sim \mathrm{USD}$ \$200.00), which was obtained from a questionnaire completed by the applicants as part of Federal University of Rio Grande do Norte's routine enrollment procedure for all applicants. Family income was classified into five ranges: $<1$ m.w., 1-5 m.w., 5-10 m.w., 10-20 m.w., and $>20$ m.w. Thus, we analyzed the percentage of subjects in each income range for each course offered. Additionally, mean income per course was calculated, based on the intermediate value of these confidence intervals.

\section{Data analysis}

In Study 1, we used the $\chi^{2}$ test to compare the data from public and private school students. In Study 2, the indicators of course difficulty were analyzed using factorial analysis with varimax rotation, resulting in only one factor, which we called the Course Difficulty Factor. We used Pearson's correlation test to analyze the relationship between the percentage of applicants from each family income range in the 2006 and 2007 entrance examinations and the Course Difficulty Factor for the previous year. Thus, we sought to determine the relationship between the subjects' choices and the information they had about the course difficulty indicators for the previous year's examination. Pearson's correlation was also used to investigate the relationship between the Course Difficulty Factor for the previous year and the mean income. A simple regression analysis was then conducted to determine the extent to which the mean income of the applicants was a variable with good explanatory power with regard to the difficulty of the chosen course. The data were statistically analyzed after the values ( $\mathrm{z}$ scores) were standardized, and a significance level of .05 was adopted $(p \leq .05)$.

\section{Results}

\section{Study 1}

Asked about their plans for the following year on an open questionnaire, the students gave 323 responses, which were grouped into categories that could include more than one answer per student. Significant differences were found between the answers of public and private school students $\left(\chi_{7}^{2}=22.59, p<.001\right.$; Figure 1). Private school students responded much more frequently that they planned to go to university the following year than the public school students $\left(\chi_{1}^{2}=5.32, p=.021\right)$, and they mentioned extracurricular activities in the leisure/ sports category three times as often $\left(\chi_{1}^{2}=4.26, p=\right.$ .039). The public school students gave more answers related to other studies $\left(\chi_{1}^{2}=8.05, p=.005\right)$, such as professionalizing, computer and language courses, and vague responses (e.g., "study"), in addition to citing work more often as their plan for the following year $\left(\chi^{2}\right.$ $=5.31, p=.021$ ).

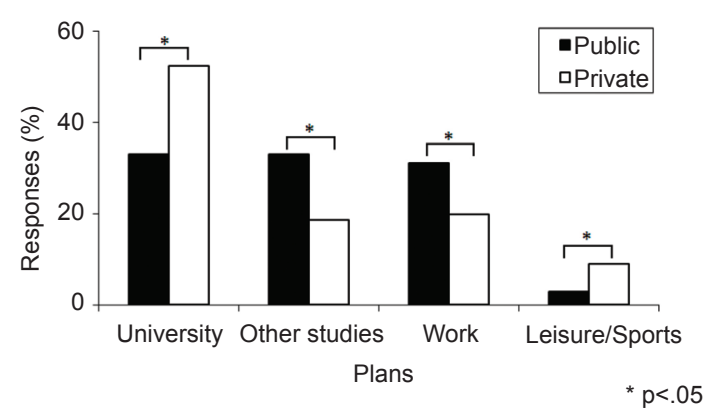

Figure 1. Distribution of the public and private school students in relation to plans for the following year ( $\mathrm{N}=323$ answers).

\section{Study 2}

Distribution of applicants according to income. An analysis of the 2006 and 2007 applicants' questionnaires showed that more than half of them were in the 1-5 m.w. range, and only a small percentage were in the $>$ 20 m.w. range. Figure 2 illustrates this distribution in 2007, which had an identical tendency to that shown in 2006. Notably, the official data from national research of households in 2006 (Instituto Brasileiro de Geografia e Estatística, 2007) indicated a high level of income inequality in the Brazilian population. Considering the family income per capita in $2006,52.4 \%$ of the families lived with $<1$ m.w., $37.6 \%$ of the families lived with 1-5 m.w., and only 5.7\% lived with $>5$ m.w. (Instituto Brasileiro de Geografia e Estatística, 2007). This population data reveal that a small percentage of the low-income population, which is the majority of the Brazilian population, has the opportunity to apply for a vacancy at a university. Interestingly, the actual access to higher education in Brazil is even more unequal. Considering the population from 18 to 
24 years of age, for example, the richest $20 \%$ occupy $74.7 \%$ of all of the vacancies at universities (Andrade, \& Dachs, 2008).

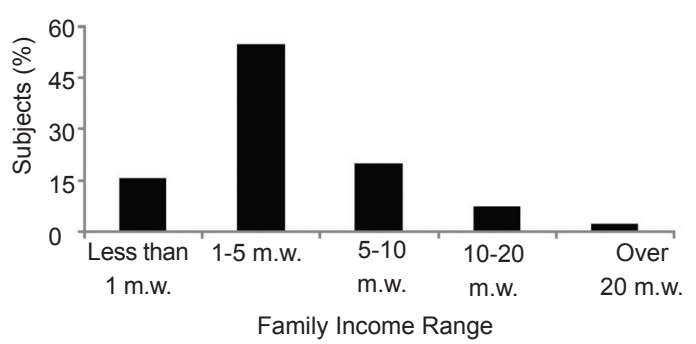

Figure 2. Distribution of entrance examination applicants according to family income ranges in 2007.

Course difficulty and family income. Our results showed that the distribution of subjects in each family income range changed according to the level of course difficulty. Factorial analysis with varimax rotation of the two variables that indicate course difficulty (i.e., applicant/vacancy ratio for each course and mean number of correct answers obtained on multiplechoice examinations by successful applicants for the previous year's examination) resulted in a measure of sampling adequacy (KMO) of .5 for 2007, explaining $83.3 \%$ of the data variance (Bartlett $<.001$ ). For 2006, we obtained a measure of sampling adequacy (KMO) of .5 , explaining $70.7 \%$ of the data variance (Bartlett $<.001)$. This Course Difficulty Factor was used for correlations with the percentages of applicants in each income range. The analysis of the 2007 data, for example, showed that the Course Difficulty Factor varied between 4.41 and -1.86 . The courses with the highest Course Difficulty Factor were Medical School (4.41), Psychology (2.15), and Law School (1.76), and those with the lowest Course Difficulty Factor were Statistics (-1.86), Music (-1.41), and Mathematics $(-1.25)$.

Comparing the courses offered at Federal University of Rio Grande do Norte in 2006 and 2007, we found negative correlations between the Course Difficulty Factor and the percentage of subjects in the $<1$ m.w. category (2006: $r=-.49, p<.001 ; 2007: r=-.48, p$ $<.001)$ and in the 1-5 m.w. range (2006: $r=-.69, p<$ $.001 ; 2007: r=-.67, p<.001)$. These findings show that a higher level of course difficulty was associated with a lower percentage of subjects in these income ranges (Figure 3a, b). The Course Difficulty Factor showed a positive correlation with higher income levels, particularly with 5-10 m.w. (2006: $r=.45, p<.001$; 2007: $r=.56, p<.001), 10-20$ m.w. (2006: $r=.74, p<$ $.001 ; 2007: r=.64, p<.001)$ and $>20$ m.w. (2006: $r=$ $.75, p<.001 ; 2007: r=.67, p<.001)$. Data from 2007

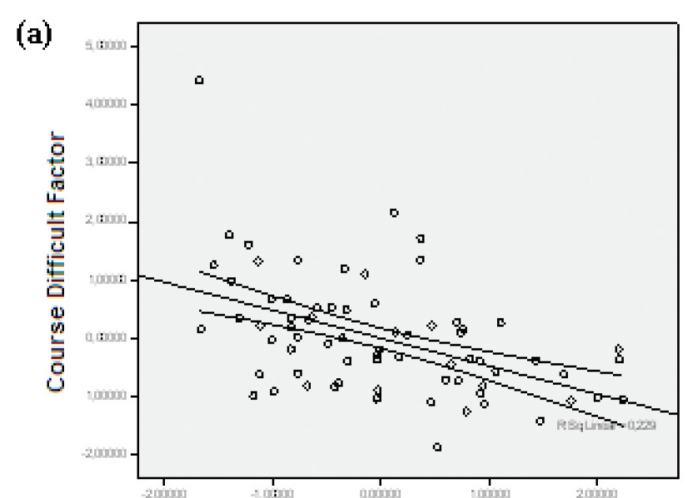

Percentage of applicants in the less than $1 \mathrm{~m} . \mathrm{w}$. family income range (Zscore)

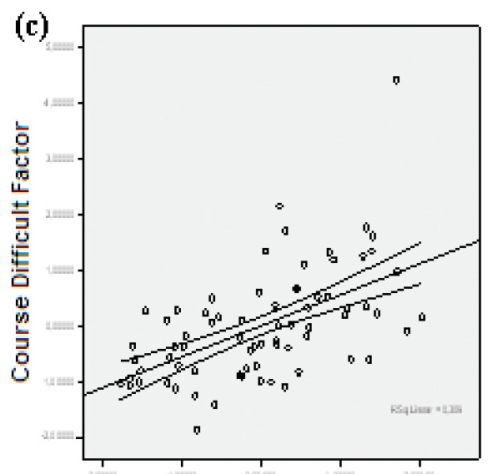

Percentage of applicants in the $5-10 \mathrm{~m}$ family income range (Zscore)

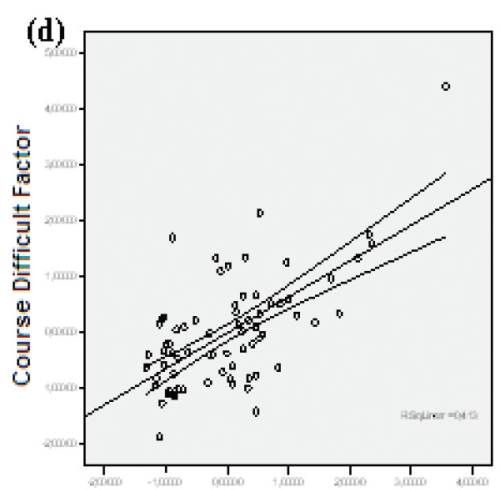

ercentage of applicants in the $10-20 \mathrm{~m} . \mathrm{w}$ family income range (Zscore)
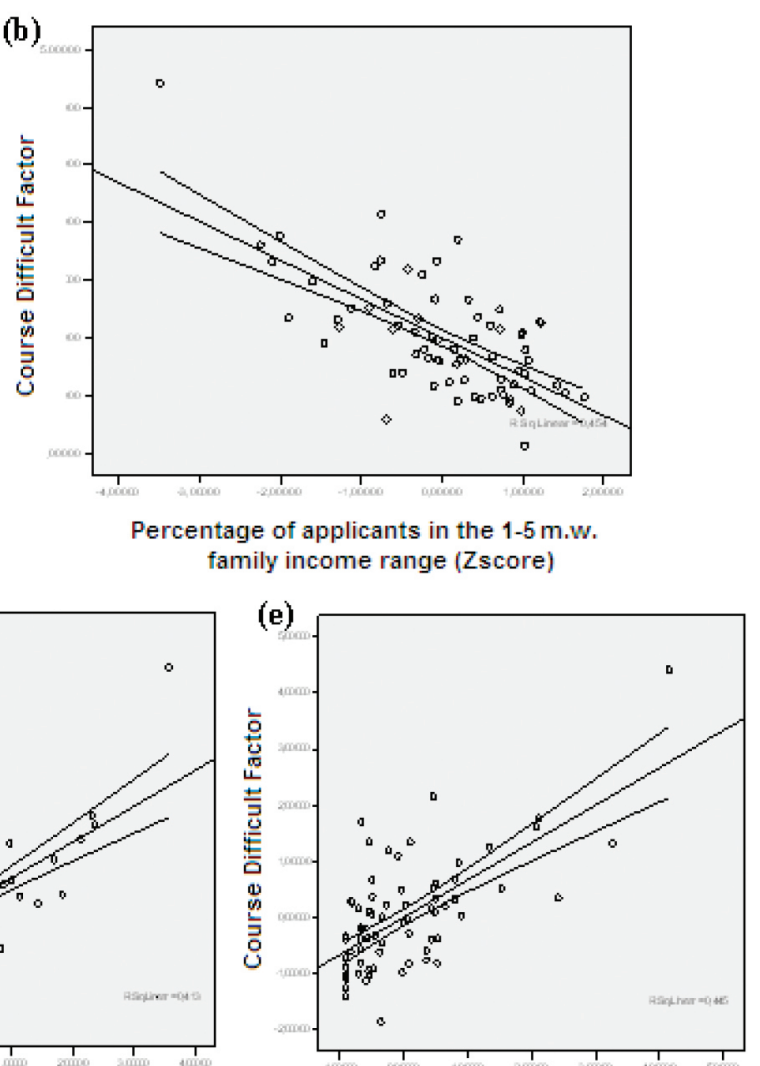

Percentage of applicants in the over $20 \mathrm{~m} . \mathrm{w}$. family income range (Zscore)

Figure 3. Course Difficulty Factor and percentage of subjects in the family income ranges: (a) less than 1 m.w.; (b) 1-5 m.w.; (c) 5-10 m.w.; (d) 10-20 m.w.; and (e) over 20 m.w. The circles represent each of the 72 courses offered by UFRN-Campus Natal in 2007. The results of the 2006 data had the same tendency shown in this figure. 
(Figure 3c-e) illustrate how these correlations become stronger as the income range increases.

These data show that subjects from families with lower incomes choose courses with a lower level of difficulty. However, as family income increases, selection tends toward courses with high levels of entrance difficulty.

Based on the intermediate value of these income ranges, we calculated the mean income for each course. We found a significant positive correlation (2006: $r=.74$, $p<.001$; 2007: $r=.66, p<.001)$ between the Course Difficulty Factor and mean income per course. Finally, we conducted a simple linear regression analysis, with mean income as the independent variable and the Course Difficulty Factor as the dependent variable. Mean wage was a good predictor of the course selected by the subject according to its difficulty (2006: $F_{1,69}=85.32, p<.001$; 2007: $F_{1,70}=58.81, p<.001$ ) (Figure 4). This means that the difficulty level of the course selected could be predicted by the mean family income of the subject.

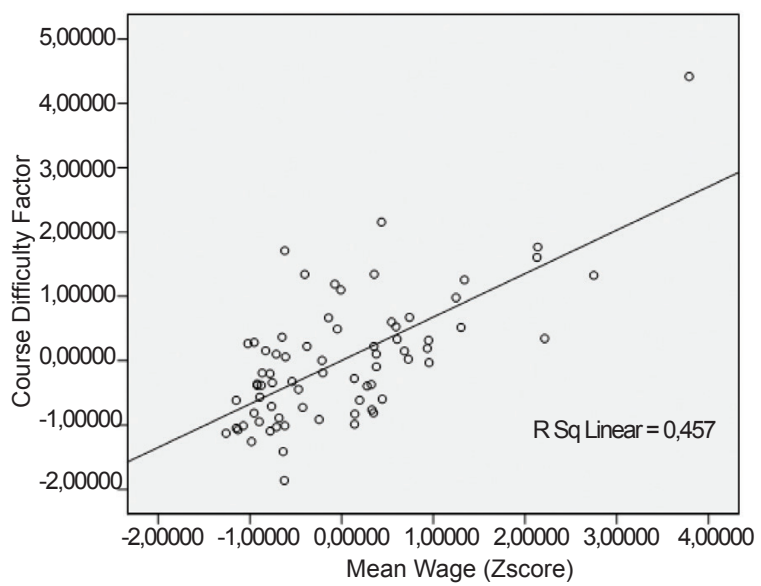

Figure 4. Correlation between Course Difficulty Factor and Mean wage income. The circles represent the 72 courses offered by UFRN-Campus Natal in 2007. The higher the applicant's mean income, the greater the difficulty level of the selected course.

\section{Discussion}

Using extensive data, this paper discusses the reallife career plans of senior high school students and the real-life career choices of applicants who intend to enter a university. Our results indicate that individuals with different incomes make different future plans and course choices based on distinct levels of entrance difficulty. We suggest that the subjects adjust their career plans and choices according to their socioeconomic conditions, considering the risks of failure and future gains.

Analyzing these findings from the future discounting perspective, we propose that subjects with lower income levels (from public schools) plan the future based on the greater likelihood of short/midterm returns, citing mainly work and other studies as immediate plans. The subjects with higher income levels (enrolled in private schools) are mainly concerned about entering a university (i.e., adopting strategies with a greater likelihood of mid/long-term returns). These results suggest that a very small portion of public school students attempt to pursue higher education. In addition, data from Study 2 indicate that those subjects, who do attempt to get access to university, make choices that are different from their higher income counterparts.

With regard to the subjects who attempt to gain entrance to a university, we suggest that low family income subjects choose courses with lower entrance difficulty as a way of discounting the future as a form of entering a university as soon as possible. Thus, these individuals can graduate earlier, enter the job market, and benefit from the rewards of university education sooner than if they choose a course with higher entrance difficulty. However, higher income individuals have financial support that enables them to bear the costs of long-term strategies (e.g., waiting one or more years for the next examinations in case they do not succeed in their first attempt and receiving private tutoring for the examination) and make greater investments, expecting to obtain better future gains when they choose courses with greater entrance difficulty.

An evolutionary analysis of these data allows us to recognize the capacity of the human mind to adjust behavior and decision-making in an adaptive way, according to environmental circumstances (Gigerenzer, \& Golstein, 1996; Hill, Thomson Ross, \& Low, 1997; Tooby, \& Cosmides, 1992). Like the most important choices in life, career choice involves deciding to invest time and energy in projects with different chances of success and significant later consequences for the individual. But how does the evolved mind decide on how much to discount the future? Wilson, \& Daly (1997) suggested that the discount rate depends on cues offered by the environment. By indicating that life expectancy affects risk assumption, these authors asserted that our mind has a semi-statistical apprehension of local life expectancy based on the fate of significant individuals. Similarly, we understand that individuals with different incomes count on environmental cues that inform them not only about available job and educational opportunities but also about the success of relatives and friends in relation to their career choices and mainly about previous successes and failures of the individuals themselves and their competitive chances with career choices that involve greater or lesser investment.

Hirschi, \& Vondracek (2009) showed interesting findings concerning this point. The authors classified each student's career goal based on its scholastic demands, from the lowest demand (educational goals that can be directly pursued after any school track) to the highest demand (a career based on a college degree that requires three or more years). The subjects' career goal adaptation over the school year in relation to scholastic achievement (scores on scholastic achievement tests) was then analyzed. The results indicated that students in basic school tracks (with lower requirements) tended to show more career adaptation to their scholastic 
achievement. Additionally, advanced track students were more likely to aspire to post-secondary education, delaying their ultimate occupational choices.

Importantly, in this study, we must not assume that individuals who choose less difficult courses have short time horizons; after all, they are seeking a university course with a mean duration of 4 to 5 years. But these individuals, when compared with individuals from more privileged social classes, are making less costly choices. It is possible to suppose that if they are compared with their peers from the same income range, then they would be valuing their future (as evidenced by Study 1), given that in Brazil, according to national demographic data, only a very small portion of the underprivileged population enters a university. Brazilian education data, for example, show that the wealthiest $20 \%$ of the population have mean schooling of 10.3 years, whereas the poorest $20 \%$ have 4.7 years of schooling (Wegrzynovski, 2008).

Indeed, future discounting must be understood as a continuum, where subjects who choose low difficulty courses are assuming intermediate discount rates. More elevated discount rates are adopted by those with similar income who make career choices that are more shortterm and that do not include a university education, opting for short technical courses or entry into the job market without further education, as suggested by Study 1. At the other extreme of the continuum are those who opt for courses with the highest difficulty factors, as suggested by Study 2 (Figure 5). What about lower income individuals who try to enter a university? What about those who choose difficult courses? These individuals may have social support or judge themselves as having competitive chances. Future studies may help explain which variables are involved in their decision making and why they make different decisions from those of most of their peers.

In the present study, we showed that other factors, such as income and future discounting strategies, in addition to social, family, and cultural variables, may help us understand the career choices made by individuals. Our findings demonstrate that the scope of the future discounting approach surpasses traditional studies and has proven to be useful for investigating multiple psychological issues.

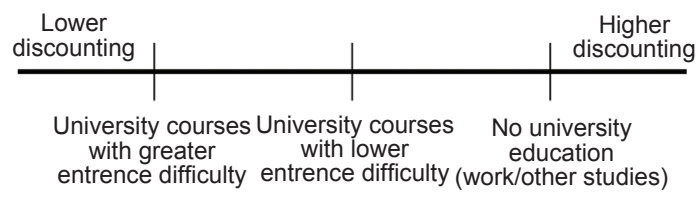

Career choices

Figure 5. Continuum of future discounting in relation to career choices.

\section{References}

Andrade, C. Y., \& Dachs, N. (2008). Uma análise do acesso à educação no Brasil por jovens de 18 a 24 anos no período de 1995 a 2006. Revista USP, 78, 32-47.

Charlton, B. G. (1996). What is the ultimate cause of socio-economic inequalities in health? An explanation in terms of evolutionary psychology. Journal of the Royal Society of Medicine, 89(1), 3-8.

Comperve - Comissão Permanente de Vestibular (2007). Seminário de Avaliação do Vestibular 2007 da UFRN. [http://www. comperve.ufrn.br/conteudo/psanteriores/ps2007/documentos/ SeminarioAvaliacaoPS2007.pdf; accessed September 2, 2009]

Daly, M., \& Wilson, M. (2005). Carpe diem: adaptation and devaluing the future. Quarterly Review of Biology, 80(1), 55-61.

Ellis, B. J., Figueredo, A. J., Brumbach, B. H., \& Schlomer, G. L. (2009). Fundamental dimensions of environmental risk: the impact of harsh versus unpredictable environments on the evolution and development of life history strategies. Human Nature, 20, 204-268.

Engqvist, L., \& Sauer, K. P. (2002). A life-history perspective on strategic mating effort in male scorpionflies. Behavioral Ecology, 13(5), 632-636.

Frederick, S., Loewenstein, G., \& O’Donoghue, T. (2002). Time discounting and time preference: a critical review. Journal of Economic Literature, 40(2), 351-401.

Fried, Y., Grant, A. M., Levi, A. S., Hadani, M., \& Slowik, L. H. (2007). Job design in temporal context: a career dynamics perspective. Journal of Organizational Behavior, 28(7), 911927.

Gigerenzer, G., \& Goldstein, D. G. (1996). Reasoning the fast and frugal way: models of bounded rationality. Psychological Review, 103(4), 650-669.

Green, L., Fry, A. F., \& Myerson, J. (1994). Discounting of delayed rewards: a life-span comparison. Psychological Science, 5(1), 33-36.

Green, L., Myerson, J., \& Ostaszewski, P. (1999). Discounting of delayed rewards across the life span: age differences in individual discounting functions. Behavioural Processes, 46(1), 89-96.

Green, L., Myerson, J., Lichtman, D., Rosen, S., \& Fry, A. (1996). Temporal discounting in choice between delayed rewards: the role of age and income. Psychology and Aging, 11(1), 79-84.

Hall, D. T., \& Chandler, D. E. (2005). Psychological success: when the career is a calling. Journal of Organizational Behavior, 26(2), 155-176.

Hardisty, D. J., \& Weber, E. U. (2009). Discouting future green: money versus the environment. Journal of Experimental Psychology: General, 138(3), 329-340.

Harrison, G. W., Lau, M. I., \& Williams, M. B. (2002). Estimating individual discount rates in Denmark: a field experiment. American Economic Review, 92(5), 1606-1617.

Hayden, B. Y., \& Platt, M. L. (2007). Temporal discounting predicts risk sensitivity in rhesus macaques. Current Biology, 17(1), 49-53.

Hesketh, B., Watson-Brown, C., \& Whiteley, S. (1998). Time-related discounting of value and decision-making about job options. Journal of Vocational Behavior, 52(1), 89-105.

Hill, E., Jenkins, J., \& Farmer, L. (2008). Family unpredictability, future discounting, and risk taking. Journal of Socio-Economics, 37, 1381-1396.

Hill, E. M., Thomson Ross, L., \& Low, B. S. (1997). The role of future unpredictability in human risk taking. Human Nature, 8(4), 287325.

Hirschi, A., \& Vondracek, F. W. (2009). Adaptation of career goals to self and opportunities in early adolescence. Journal of Vocational Behavior, 75(2), 120-128.

Hwang, J., Kim, S., \& Lee, D. (2009). Temporal discounting and inter-temporal choice in rhesus monkeys. Frontiers in Behavioral Neuroscience, 3, 9.

Instituto Brasileiro de Geografia e Estatística (2007). Síntese de indicadores sociais 2007. Uma análise das condições de vida da população brasileira. Série Estudos e Pesquisas - Informação demográfica e socioeconômica - Número 21. Rio de Janeiro: IBGE.

Kaplan, G. A., Kamuk, E. R., Lynch, J. V. V., Cohen, R. D., \& Balfour, J. L. (1996). Inequality in income and mortality in the United States: analysis of mortality and potential pathways. British Medical Journal, 312(7037), 999-1003 [erratum: 312(7041), 1253]. 
Kirby, K. N., \& Marakovic, N. N. (1996). Delay-discounting probabilistic rewards: rates decrease as amounts increase. Psychonomic Bulletin and Review, 3(1), 100-104.

Kirby, K. N., Petry, N. M., \& Bickel, W. K. (1999). Heroin addicts have higher discount rates for delayed rewards than non-drug-using controls. Journal of Experimental Psychology: General, 128(1), 78-87.

Kollins, S. H. (2003). Delay discounting is associated with substance use in college students. Addictive Behaviors, 28(6), 1167-1173.

Matta, A., Gonçalves, F. L., \& Bizarro, L. (2012). Delay discounting: concepts and measures. Psychology and Neuroscience, 5(2), 135 146.

Mischel, W., Shoda, Y., \& Rodriguez, M. I. (1989). Delay of gratification in children. Science, 244(4907), 933-938.

Muramatsu, R., \& Fonseca, P. (2008). Economia e psicologia na explicacao da escolha intertemporal. Revista de Economia Mackenzie, 6(1), 87-112.

Nettle, D. (2010). Dying young and living fast: variation in life history across English neighborhoods. Behavioral Ecology, 21, 387-395.

Ramos, D., Victor, T., Seidl-de-Moura, M. L., \& Daly, M. (2013). Future discounting by slum-dwelling youth versus university students in Rio de Janeiro. Journal of Research on Adolescence, 23(1), 95-102.

Reimers, S., Maylor, E. A., Stewart, N., \& Chater, N. (2009). Associations between a one-shot delay discounting measure and age, income, education and real-world impulsive behavior. Personality and Individual Differences, 47(8), 973-978.

Reynolds, B., Patak, M., \& Shroff, P. (2007). Adolescent smokers rate delayed rewards as less certain than adolescent nonsmokers. Drug and Alcohol Dependence, 90(2-3), 301-303.

Rogers, A. R. (1994). Evolution of time preference by natural selection. American Economic Review, 84(3), 460-481.

Roitberg, B. D., Mangel, M., Lalonde, R. G., Roitberg, C. A., van Alphen, J. J. M., \& Vet, L. (1992). Seasonal dynamic shifts in patch exploitation by parasitic wasps. Behavioral Ecology, 3(2), 156-165.
Roitberg, B. D., Sircom, J., Roitberg, C. A., van Alphen, J. J. M., \& Mangel, M. (1993). Life expectancy and reproduction. Nature, 364(6433), 108

Rosati, A. G., Stevens, J. R., Hare, B., \& Hauser, M. D. (2007). The evolutionary origins of human patience: temporal preferences in chimpanzees, bonobos, and human adults. Current Biology, 17(19), 1663-1668.

Saunders, R., \& Fogarty, G. (2001). Time discounting in relation to career preferences. Journal of Vocational Behavior, 58(1), 118-126.

Schoenfelder, T. E., \& Hantula, D. A. (2003). A job with a future? Delay discounting, magnitude effects, and domain independence of utility for career decisions. Journal of Vocational Behavior, 62(1), 43-55.

Steinberg, L., Graham, S., O’Brien, L., Woolard, J., Cauffman, E., \& Banich, M. (2009). Age differences in future orientation and delay discounting. Child Development, 80(1), 28-44.

Stevens, J. R., Hallinan, E. V., \& Hauser, M. D. (2005). The ecology and evolution of patience in two New World monkeys. Biology Letters, 1(2), 223-226.

Tooby, J. H., \& Cosmides, L. (1992). The psychological foundations of culture. In J. H. Barkow, L. Cosmides, \& J. Tooby (Eds.), The adapted mind: evolutionary psychology and the generation of culture (pp. 19-136). New York: Oxford University Press.

Wegrzynovski, R. (2008). Ensino - Ainda vítima das iniqüidades. Revista Desafios do Desenvolvimento, 40, 38-45.

Whelan, R., \& McHugh, L. A. (2009). Temporal discounting of hypothetical monetary rewards by adolescents, adults, and older adults. Psychological Record, 59(2), 247-258.

Wilkinson, R. G. (1992). Income distribution and life expectancy. British Medical Journal, 304(6820), 165-168.

Wilson, M., \& Daly, M. (1997). Life expectancy, economic inequality, homicide, and reproductive timing in Chicago neighbourhoods. British Medical Journal, 314(7089), 1271-1274.

Wilson, M., \& Daly, M. (2004). Do pretty women inspire men to discount the future? Proceedings of the Royal Society B, Biological Sciences, 271(Suppl. 4), S177-S179.

Wilson, M., \& Daly, M. (2006). Are juvenile offenders extreme future discounters? Psychological Science, 17(11), 989-994.

Woyciechowski, M., \& Kozlowski, J. (1998). Division of labor by division of risk according to worker life expectancy in the honey bee (Apis mellifera L.). Apidologie, 29(1-2), 191-205. 